\title{
Meal-derived glucagon responses are related to lower hepatic phosphate concentrations in obesity and type 2 diabetes
}

Citation for published version (APA):

Weber, K. S., Strassburger, K., Fritsch, M., Bierwagen, A., Koliaki, C., Phielix, E., Pacini, G., Hwang, J-H., Markgraf, D. F., Burkart, R., Muessig, K., Szendroedi, J., \& Roden, M. (2018). Meal-derived glucagon responses are related to lower hepatic phosphate concentrations in obesity and type 2 diabetes. Diabetes \& Metabolism, 44(5), 444-448. https://doi.org/10.1016/j.diabet.2018.05.008

Document status and date:

Published: 01/11/2018

DOI:

10.1016/j.diabet.2018.05.008

Document Version:

Publisher's PDF, also known as Version of record

Document license:

Taverne

Please check the document version of this publication:

- A submitted manuscript is the version of the article upon submission and before peer-review. There can be important differences between the submitted version and the official published version of record.

People interested in the research are advised to contact the author for the final version of the publication, or visit the DOI to the publisher's website.

- The final author version and the galley proof are versions of the publication after peer review.

- The final published version features the final layout of the paper including the volume, issue and page numbers.

Link to publication

\footnotetext{
General rights rights.

- You may freely distribute the URL identifying the publication in the public portal. please follow below link for the End User Agreement:

www.umlib.nl/taverne-license

Take down policy

If you believe that this document breaches copyright please contact us at:

repository@maastrichtuniversity.nl

providing details and we will investigate your claim.
}

Copyright and moral rights for the publications made accessible in the public portal are retained by the authors and/or other copyright owners and it is a condition of accessing publications that users recognise and abide by the legal requirements associated with these

- Users may download and print one copy of any publication from the public portal for the purpose of private study or research.

- You may not further distribute the material or use it for any profit-making activity or commercial gain

If the publication is distributed under the terms of Article $25 \mathrm{fa}$ of the Dutch Copyright Act, indicated by the "Taverne" license above, 
Short Report

\title{
Meal-derived glucagon responses are related to lower hepatic phosphate concentrations in obesity and type 2 diabetes
}

\author{
K.S. Weber ${ }^{a, b}$, K. Straßburger ${ }^{\text {b,c }}$, M. Fritsch ${ }^{\text {a,b,d }}$, A. Bierwagen ${ }^{\text {a,b }}$, C. Koliaki ${ }^{\text {a,b,e,f }}$, \\ E. Phielix $^{\text {a,b,g }}$, G. Pacini ${ }^{\text {h }}$, J.-H. Hwang ${ }^{a, b}$, D.F. Markgraf ${ }^{a, b}$, V. Burkart ${ }^{a, b}$, K. Müssig ${ }^{\text {a,b,e, }}$, \\ J. Szendroedi ${ }^{\mathrm{a}, \mathrm{b}, \mathrm{e}}$, M. Roden ${ }^{\mathrm{a}, \mathrm{b}, \mathrm{e}, *}$ \\ ${ }^{a}$ Institute for Clinical Diabetology, German Diabetes Centre at Heinrich Heine University, Leibniz Centre for Diabetes Research, Düsseldorf, Germany \\ ${ }^{\mathrm{b}}$ German Centre for Diabetes Research (DZD), München-Neuherberg, Germany \\ ${ }^{\mathrm{c}}$ Institute for Biometrics and Epidemiology, German Diabetes Centre at Heinrich Heine University, Leibniz Centre for Diabetes Research, Düsseldorf, Germany \\ ${ }^{\mathrm{d}}$ Department of Pediatric and Adolescent Medicine, Medical University of Vienna, Vienna, Austria \\ e Division of Endocrinology and Diabetology, Medical Faculty, Heinrich Heine University Düsseldorf, Düsseldorf, Germany \\ ${ }^{\mathrm{f}}$ Athens University Medical School, Athens, Greece \\ ${ }^{\mathrm{g}}$ Department of Human Biology and Movement Sciences, NUTRIM school for Nutrition, Toxicology and Metabolism, Maastricht University Medical Centre, \\ Maastricht, Netherlands \\ ${ }^{\mathrm{h}}$ Metabolic Unit, Institute of Neuroscience, National Research Council, Padova, Italy
}

\section{A R T I C L E I N F O}

\section{Article history:}

Received 21 November 2017

Received in revised form 30 April 2018

Accepted 23 May 2018

Available online 2 June 2018

\section{Keywords:}

Adipose tissue

Glucagon

GIP

GLP-1

Hepatic fat content

Insulin sensitivity

\begin{abstract}
A B S T R A C T
Aim. - Type 2 diabetes (T2D) alters glucagon, glucagon-like peptide (GLP)-1, glucose-dependent insulinotropic polypeptide (GIP) and hepatic energy metabolism, yet the possible relationships remain unclear.

Methods. - In this observational study, lean insulin-sensitive control subjects (BMI: $23.2 \pm 1.5 \mathrm{~kg} / \mathrm{m}^{2}$ ), age-matched insulin-resistant obese subjects (BMI: $34.3 \pm 1.7 \mathrm{~kg} / \mathrm{m}^{2}$ ) and similarly obese elderly T2D patients (BMI: $32.0 \pm 2.4 \mathrm{~kg} / \mathrm{m}^{2}$ ) underwent mixed-meal tolerance tests (MMTTs), and assessment of hepatic $\gamma$ ATP, inorganic phosphate $\left(\mathrm{P}_{\mathrm{i}}\right)$ and lipids using ${ }^{31} \mathrm{P} /{ }^{1} \mathrm{H}$ magnetic resonance spectroscopy. Meal-induced secretion of glucagon and incretins was calculated from incremental areas under the concentration-time curves (iAUCs). Peripheral and adipose tissue insulin sensitivity were assessed from time courses of circulating glucose, insulin and free fatty acids.

Results. - MMTT-derived peripheral insulin sensitivity was lowest in T2D patients $(P<0.001)$, while glucagon concentrations were comparable across all three groups. At $260 \mathrm{~min}, \mathrm{GLP}-1$ was lower in T2D patients than in controls, whereas GIP was lowest in obese individuals. Fasting glucagon concentrations correlated positively with fasting $(r=0.60)$ and postprandial hepatocellular lipid levels (160 min: $r=0.51,240 \mathrm{~min}: r=0.59)$, and negatively with adipose tissue insulin sensitivity $(r=-0.73)$. Higher meal-induced glucagon release $\left(\mathrm{iAUC}_{0-260} \mathrm{~min}\right)$ correlated with lower fasting $(r=-0.62)$ and postprandial $P_{\mathrm{i}}$ levels (160 min: $r=-0.43,240 \mathrm{~min}: r=-0.42$; all $\left.P<0.05\right)$. Higher meal-induced release of GIP (iAUC $0-260 \mathrm{~min})$ correlated positively with fasting $(r=0.54)$ and postprandial serum triglyceride concentrations ( $\mathrm{iAUC}_{0-260 \mathrm{~min}}, r=0.54$; all $P<0.01$ ).

Conclusion. - Correlations between fasting glucagon and hepatic lipids and between meal-induced glucagon and hepatic $P_{i}$ suggest a role for glucagon in hepatic energy metabolism.
\end{abstract}

(c) 2018 Elsevier Masson SAS. All rights reserved.

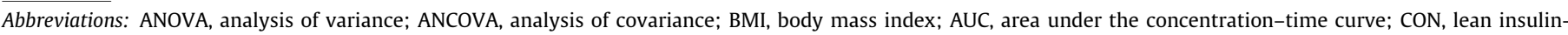

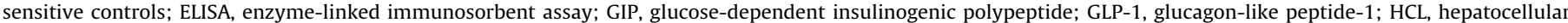

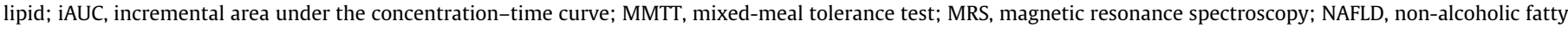

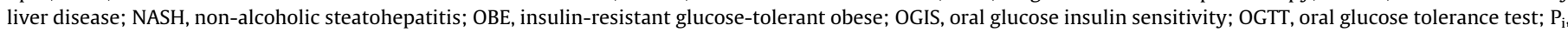
inorganic phosphate; $\gamma$ ATP, gamma-adenosine triphosphate; SCaMC, small calcium-binding mitochondrial carrier; T2D, type 2 diabetes.

* Corresponding author at: Division of Endocrinology and Diabetology, Medical Faculty, Heinrich Heine University, Düsseldorf, Institute for Clinical Diabetology, German Diabetes Centre, Heinrich-Heine University, c/o Aufm Hennekamp 65, 40225 Düsseldorf, Germany.

E-mail address: michael.roden@ddz.uni-duesseldorf.de (M. Roden). 


\section{Introduction}

In obese individuals with non-alcoholic fatty liver disease (NAFLD), postprandial adaptation of hepatic energy metabolism to higher substrate flux is enhanced, leading to hepatic oxidative stress, which may predispose to non-alcoholic steatohepatitis (NASH) [1,2]. Patients with type 2 diabetes (T2D) also frequently present with increased hepatocellular lipid (HCL) content, which is associated with hepatic insulin resistance, impaired energy metabolism and oxidative stress [3]. Of note, the ability of glucagon to stimulate hepatic gluconeogenesis is increased in progressive NAFLD (or, specifically, NASH) [4]. Glucagon-like peptide (GLP)-1 and glucose-dependent insulinogenic polypeptide (GIP) may also contribute to hepatic energy metabolism by modulating postprandial insulin and glucagon secretion. However, the role of glucagon and incretins in the control of postprandial hepatic energy metabolism in humans is as yet unclear.

Thus, the present study aimed to test the hypothesis that glucagon concentrations are inversely related to hepatic energy metabolism, and to assess the effects of fasting and mixed-meal tolerance test (MMTT)-induced changes to plasma glucagon concentrations on hepatic energy metabolism and tissue-specific insulin sensitivity in lean insulin-sensitive control subjects (CON), age-matched insulin-resistant but glucose-tolerant obese individuals (OBE) and elderly obese patients with T2D. The secondary aim of the study was to additionally assess these associations in relation to GLP-1 and GIP.

\section{Methods}

The study design and population have already been described in detail elsewhere [1]. The trial was registered at https:// clinicaltrials.gov (NCT01229059). Briefly, between March 2012 and October 2013, 10 CON, 10 age-matched OBE and 10 elderly obese patients with T2D (Table S1 (see supplementary materials associated with this article online) underwent a standardized liquid MMTT $(2728 \mathrm{~kJ}, 83.6 \mathrm{~g}$ of carbohydrates, $23.2 \mathrm{~g}$ of protein, $24.0 \mathrm{~g}$ of fat), with blood samples taken under fasting and postprandial conditions. Composition of the MMTT was identical to that of a previous study, which demonstrated higher post-meal hepatic de-novo lipogenesis in insulin-resistant than in insulin-sensitive individuals [5]. ${ }^{31} \mathrm{P} /{ }^{1} \mathrm{H}$ magnetic resonance spectroscopy (MRS) was performed before and at $160 \mathrm{~min}$ and 240 min after meal ingestion.

For 3 days prior to the clinical visit, participants adhered to a balanced isocaloric diet and refrained from physical activity and alcohol consumption. Also, patients with T2D stopped their glucose-lowering or lipid-lowering medication for at least 3 days prior to the visits. In addition, all subjects gave their written informed consent to participate in the study, which was approved by the local ethics board [1].

Measurements of circulating glucose, C-peptide, insulin and triglyceride concentrations, as well as MRS-based quantification of $\mathrm{HCL}$, gamma-adenosine triphosphate ( $\gamma \mathrm{ATP}$ ) and inorganic phosphate $\left(\mathrm{P}_{\mathrm{i}}\right)$ have been previously described [1]. Plasma glucagon was assessed using radioimmunoassay (EMD Millipore, Saint Charles, MO, USA) before and 15, 30, 60, 90, 120, 180 and 260 min after meal ingestion. Using identical time points, plasma GIP was measured using enzyme-linked immunosorbent assay (ELISA) for human total GIP (EMD Millipore). Measurements of the bioactive form of plasma GLP-1 (7-36) were performed before and 15, 30, 60, 90 and 260 min after meal ingestion, using high-sensitivity GLP-1 ELISA (Epitope Diagnostics Inc., San Diego, CA, USA).

Areas under the concentration-time curves (AUCs) for glucagon, GLP-1 and GIP were calculated, using the trapezoidal method and corrected for fasting (basal) incretin release, to yield the incremental AUC (iAUC). Peripheral insulin sensitivity was calculated by applying the oral glucose tolerance test (OGTT)based formula for oral glucose insulin sensitivity (OGIS) index to the MMTT [6]. Adipose tissue insulin sensitivity was derived from mathematical modelling of free fatty acid and insulin concentrations [7].

Non-normally distributed variables (serum triglycerides, glucagon, HCL, GLP-1, GIP) were 1n-transformed to improve normality. Comparisons between groups at every time point of the MMTT were performed using covariance pattern analysis, which considers dependency between observations at different time points on specific subjects, with Bonferroni-based Dunn's test to correct for multiple comparisons. Analysis of variance (ANOVA) was applied to test for differences in the AUCs between groups, with Bonferroni correction for multiple comparisons [1]. Also, by applying the Wilcoxon signed-rank test to the iAUCs of glucagon, GIP and GLP-1, it was possible to test whether concentrations of these hormones significantly increased during the MMTT. Partial Pearson correlation coefficients $(r)$ and corresponding $P$ values were calculated based on the entire study sample, and adjusted for group effect, age, gender and body mass index (BMI). Interactions between groups were analyzed by two-way analysis of covariance (ANCOVA).

\section{Results}

MMTT-derived peripheral insulin sensitivity (OGIS) was lowest in T2D patients and highest in CON, whereas adipose tissue insulin sensitivity was comparable between groups (Table S1). In addition, after MMTT ingestion, GIP and GLP-1 concentrations increased in all groups, while glucagon levels increased only in patients with T2D, from $90.7 \pm 1.5 \mathrm{pg} / \mathrm{mL}$ to a maximum of $111.1 \pm 1.5 \mathrm{pg} / \mathrm{mL}$ at $30 \mathrm{~min}$ (all $P<0.004$ ). When comparing hormone levels among the CON, OBE and T2D at a single time point during the MMTT, glucagon levels did not differ across groups (Fig. S1A, B (see supplementary materials associated with this article online), whereas GLP-1 levels at fasting and at 260 min were lower in T2D compared with CON (Fig. S1G, H (see supplementary materials associated with this article online), and GIP 260 min was lower in OBE than in either CON or T2D groups (Fig. S1D, E (see supplementary materials associated with this article online). In addition, AUCs for glucagon, GLP-1 and GIP were comparable across all three groups (Fig. S1C, F (see supplementary materials associated with this article online).

GLP-1 iAUC $_{0-260} \min (r=-0.43, P=0.044$; Fig. $1 \mathrm{~A})$ and fasting glucagon ( $r=-0.73, P<0.001$ ) (Fig. 1B) were inversely correlated with adipose tissue insulin sensitivity. Higher fasting glucagon, but not glucagon $\mathrm{iAUC}_{0-260 \mathrm{~min}}$, correlated with higher $\mathrm{HCL}$ at fasting, at $160 \mathrm{~min}$ and at $240 \mathrm{~min}$ (Fig. 1C, Table S2 (see supplementary materials associated with this article online). Also, glucagon $\mathrm{iAUC}_{0-260}$ min did not correlate with the change in $\mathrm{HCL}\left(\Delta \mathrm{HCL}_{160}\right.$ min fasting: $r=0.19, P=0.354$ and $\Delta \mathrm{HCL}_{240}$ min fasting: $r=0.17$, $P=0.415)$. Higher glucagon $\mathrm{iAUC}_{0-260}$ min was correlated with lower $P_{i}$ at fasting, at $160 \mathrm{~min}$ and at $240 \mathrm{~min}$, but did not correlate with $\gamma$ ATP (Fig. 1D, Table S2). Exclusion of the outlier in the CON group did not affect the results of our correlation analyses.

GIP $\mathrm{AUC}_{0-260}$ min correlated with fasting serum triglycerides and the serum triglyceride $\mathrm{iAUC}_{0-260} \min (r=0.54, P=0.005$ and $r=0.54, P=0.005$, respectively; Fig. $1 \mathrm{E}, \mathrm{F}$ ), whereas there was no correlation between fasting GIP and either fasting serum triglycerides $\left(r=0.18, P=0.379\right.$ ) or serum triglyceride iAUC $_{0-260}$ $\min (r=0.11, P=0.610)$. Also, it is worth noting that all correlations were independent of age, gender and BMI, and there were no significant interactions between CON, OBE and T2D patients. 
A

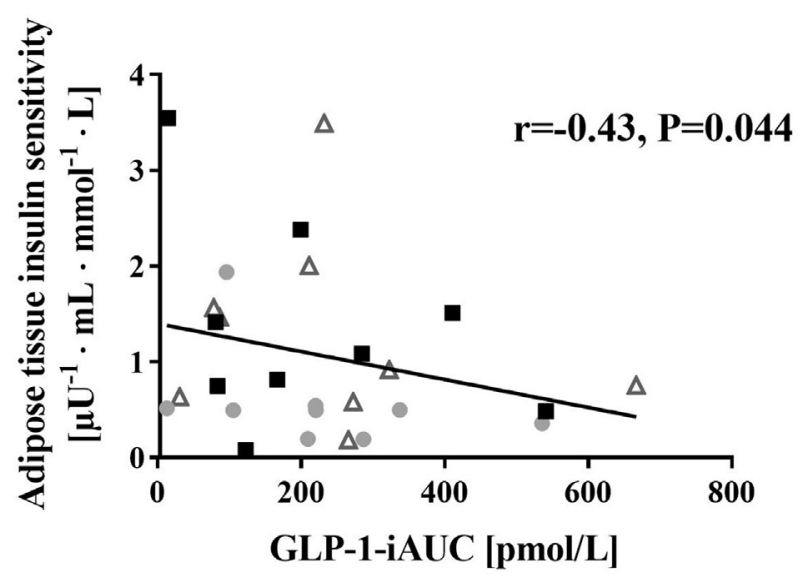

C
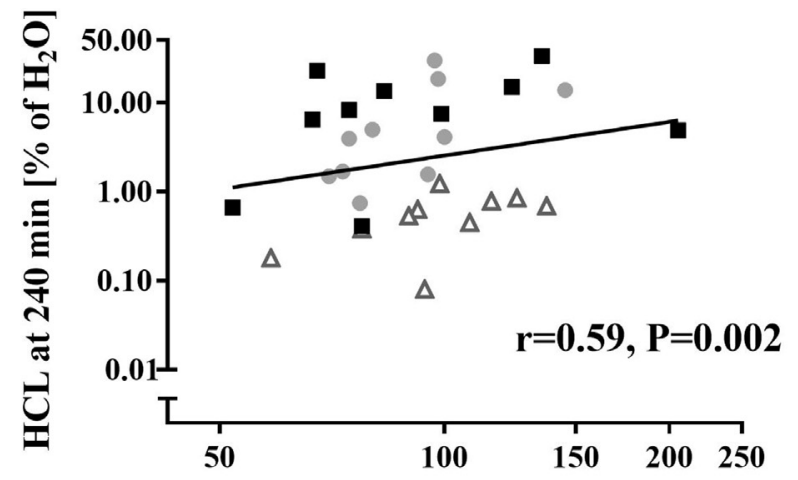

Fasting glucagon $[\mathrm{pg} / \mathrm{mL}]$

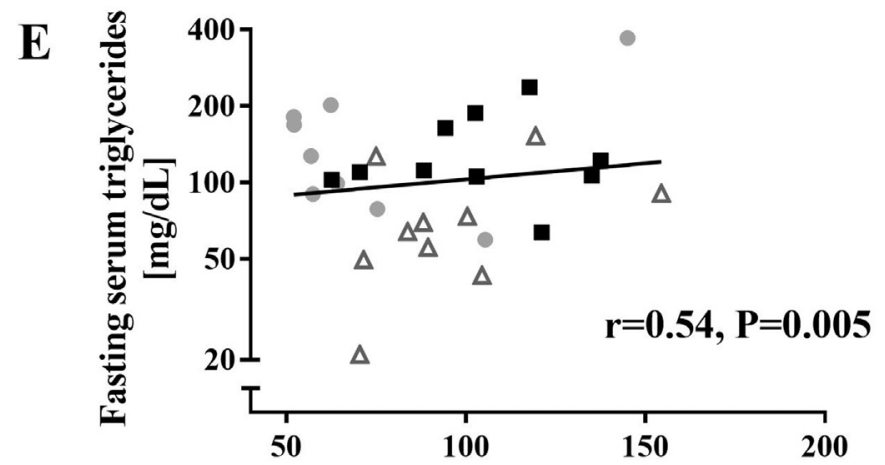

GIP-iAUC [ng $\left.\cdot \mathrm{mL}^{-1} \cdot 260 \mathrm{~min}\right]$
B

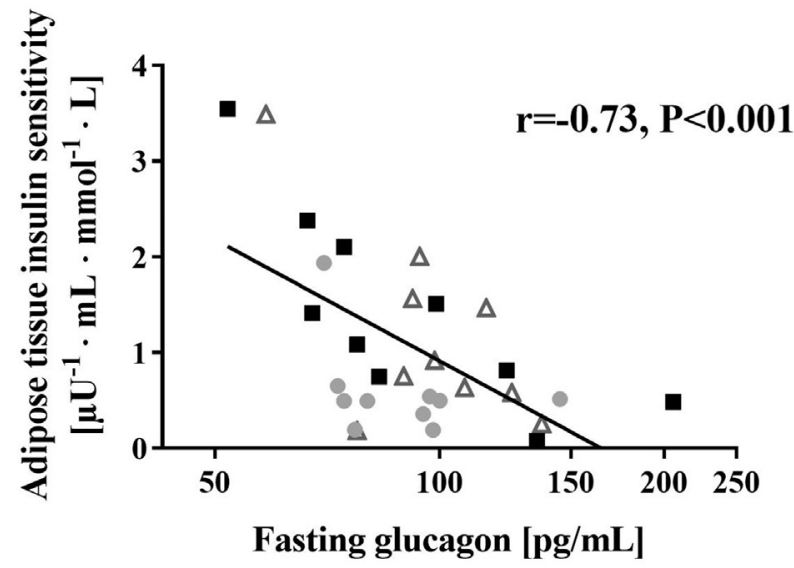

D

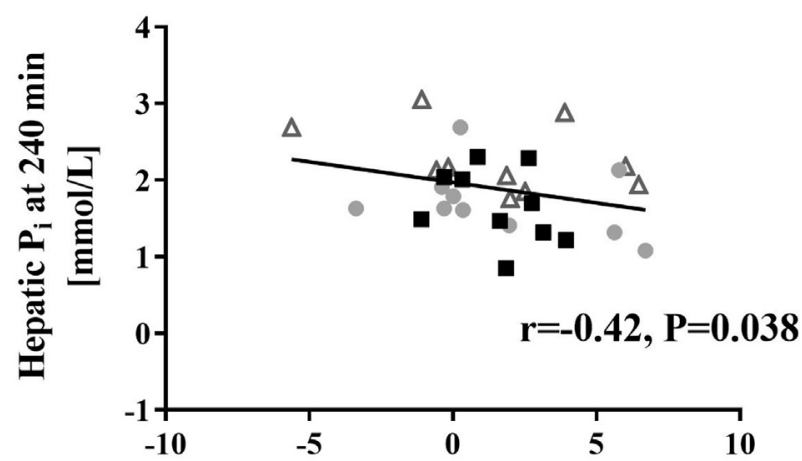

Glucagon-iAUC $\left[\mathrm{ng} \cdot \mathrm{mL}^{-1} \cdot 260 \mathrm{~min}\right]$
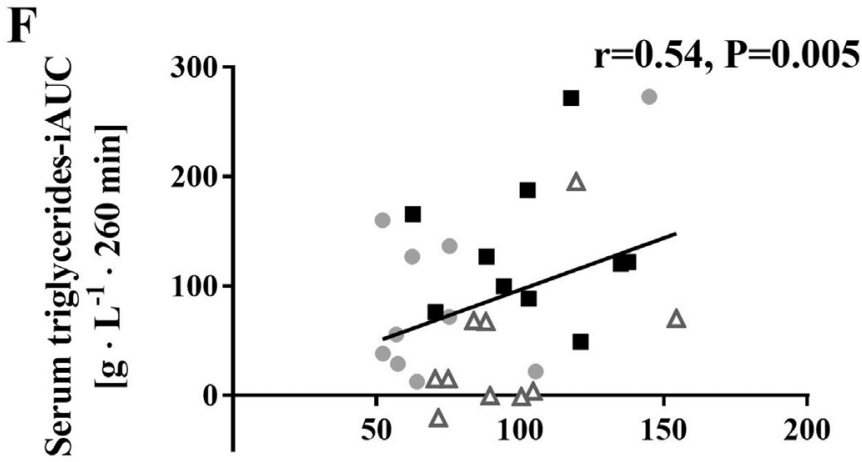

GIP-iAUC $\left[\mathrm{ng} \cdot \mathrm{mL}^{-1} \cdot 260 \mathrm{~min}\right]$

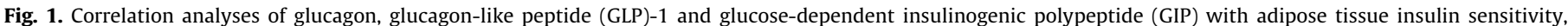

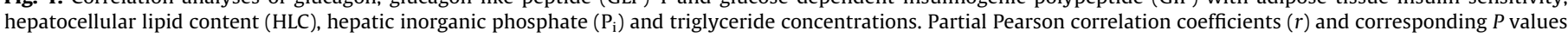

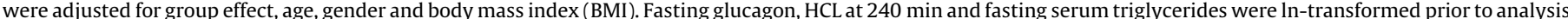

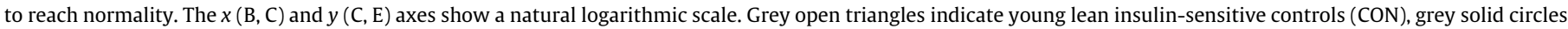

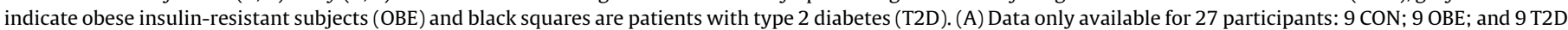
patients. iAUC: incremental area under the concentration curve.

\section{Discussion}

The present study results indicate that:

- higher meal-induced glucagon secretion correlates with lower fasting and postprandial hepatic phosphate concentrations;

- higher fasting glucagon concentrations correlate with lower adipose tissue insulin sensitivity, but also with higher fasting and postprandial HCL;

- postprandial GIP secretion directly correlates with fasting and postprandial serum triglyceride concentrations.
Glucagon is known to inhibit glycolysis [8]. However, lower glycolytic ATP production is partially balanced by a glucagoninduced increase in mitochondrial oxidative phosphorylation [8]. In mice, the stimulatory effect of glucagon on hepatic mitochondrial oxidation has been shown to be mediated by calcium signalling through inositol 1,4,5-trisphosphate receptor-1 [9]. Calcium has, in addition, long been known to be essential for glucagon-induced stimulation of gluconeogenesis [10]. Moreover, calcium stimulation of the murine mitochondrial ATP- $\mathrm{Mg} / \mathrm{P}_{\mathrm{i}}$ small calcium-binding mitochondrial carrier (SCaMC)-3 has been described to couple 
respiration and oxidative phosphorylation in response to glucagon [8]. The inverse correlation between glucagon secretion and hepatic $P_{i}$ concentrations observed in the present study suggests that glucagon might be decreasing mitochondrial oxidative phosphorylation instead of mitochondrial coupling.

The reduced adipose tissue insulin sensitivity under conditions of higher fasting glucagon concentrations might also have contributed to higher levels of circulating triglycerides and free fatty acids by augmented lipid flux to the liver [11], an idea supported by the observed direct correlation between fasting glucagon and HCL. Elevated plasma free fatty acid concentrations have been also shown to cause hepatic insulin resistance and to stimulate gluconeogenesis [11], which might lower hepatic ATP and $\mathrm{P}_{\mathrm{i}}$ concentrations.

Of note, although glucagon increased from $90.7 \pm 1.5 \mathrm{pg} / \mathrm{mL}$ to only $111.1 \pm 1.5 \mathrm{pg} / \mathrm{mL}$ in our T2D patients, it has previously been shown that even minor changes in glucagon can significantly affect hepatic glucose metabolism and, thus, are of physiological relevance [12]. Furthermore, the comparable glucagon concentrations between those with and without T2D in our study were somewhat unexpected, as inappropriate hyperglucagonaemia has been described as a common feature of T2D [13]. However, such similar glucagon concentrations have been reported previously [14] and could be due to the rather short duration (5.7 years) of known diabetes [1] and relatively good glucometabolic control of the T2D patients in our study (Table S1).

Although glucose concentrations were higher in both OBE and T2D groups compared with CON after MMTT, insulin secretion was increased only in the OBE while remaining comparable between the T2D and CON [1], most likely due to impaired incretin secretion and/or efficacy in T2D. While fasting GIP concentrations have previously been shown to have links with both fasting and mealstimulated serum triglycerides in individuals with normal/ impaired glucose tolerance or T2D [15], the present results indicate that meal-stimulated rather than fasting GIP secretion influences circulating triglycerides.

The strengths of our present study are, first, the inclusion of insulin-sensitive subjects, glucose-tolerant yet insulin-resistant individuals and T2D patients, thereby allowing direct comparisons of these metabolic states. Second, hepatic energy metabolism was monitored non-invasively by absolute quantification of hepatic ATP concentrations using in-vivo ${ }^{31} \mathrm{P}$ MRS, which reflects unidirectional flux through hepatic ATP synthase [3]. Third, covariance pattern analyses, which fully explore time effects, were applied for comparisons of incretin and glucagon responses to MMTT between groups.

On the other hand, one study limitation is the small number of participants in each of our three heterogeneous groups. It should be noted that a sample size of 30 ensures that an association between adipose tissue insulin sensitivity, $\mathrm{HCL}, \mathrm{P}_{\mathrm{i}}$, serum triglyceride and hormone concentrations can be detected with a power of $80 \%$ if the corresponding partial correlation, adjusted for up to four potential confounders, is $\geq 0.52$. Thus, our present results require confirmation in studies with larger sample sizes and more homogeneous groups of OBE and T2D patients. Another limitation is that hepatic ATP concentrations represent only one feature of hepatic energy metabolism [4].

In conclusion, meal-stimulated glucagon and GIP secretion may play a role in postprandial regulation of hepatic energy metabolism and circulating triglycerides. Further research is now warranted to determine the molecular mechanisms by which glucagon and incretins act on hepatic energy metabolism and NAFLD.

\section{Funding}

This study was supported in part by the Ministry of Innovation, Science and Research of North Rhine-Westphalia (MIWF NRW),
German Federal Ministry of Health (BMG), a grant from the Federal Ministry of Education and Research (BMBF) to the German Centre for Diabetes Research (DZD e.V.), the German Research Foundation (DFG; SFB 1116, to M.R. and J.S.), the Schmutzler-Stiftung (to M.R.) and a European Society of Paediatric Endocrinology research fellowship sponsored by Novo Nordisk A/S (to M.F.).

\section{Contribution statement}

K.S.W. wrote the manuscript and analyzed the data; K.S. supervised and gave input on the performance of the statistical analyses; M.F., A.B., C.K., E.P. and J.S. researched data; G.P. assessed metabolic parameters by running the mathematical models; A.B. and J.-H.H. contributed to the methods; D.F.M. performed laboratory analyses; J.S., K.M., V.B. and M.R. contributed to the discussion, and reviewed and edited the manuscript; and J.S. and M.R. designed the study. M.R. is the guarantor of the work and, as such, had full access to all data in the study, and takes responsibility for the integrity of the data and accuracy of the data analysis. All authors read and approved the final manuscript.

\section{Disclosure of interest}

The authors declare that they have no competing interest.

\section{Acknowledgements}

We thank Daniela Seeger, Kai Tinnes, Myrko Esser, Andrea Nagel and Nicole Achterath for their excellent technical assistance with measurements of incretin and glucagon levels and MRS studies.

\section{Appendix A. Supplementary data}

Supplementary data associated with this article can be found, in the online version, at Supplementary materials (Tables S1, Table S2 and Fig. S1) associated with this article can be found at http:// www.sciencedirect.com and https://doi.org/10.1016/j.diabet. 2018.05.008.

\section{References}

[1] Fritsch M, Koliaki C, Livingstone R, Phielix E, Bierwagen A, Meisinger M, et al. Time course of postprandial hepatic phosphorus metabolites in lean, obese, and type 2 diabetes patients. Am J Clin Nutr 2015;102:1051-8. http:// dx.doi.org/10.3945/ajcn.115.107599.

[2] Koliaki C, Roden M. Hepatic energy metabolism in human diabetes mellitus, obesity and non-alcoholic fatty liver disease. Mol Cell Endocrinol 2013;379:35-42. http://dx.doi.org/10.1016/j.mce.2013.06.002.

[3] Szendroedi J, Chmelik M, Schmid AI, Nowotny P, Brehm A, Krssak M, et al. Abnormal hepatic energy homeostasis in type 2 diabetes. Hepatol Baltim Md 2009;50:1079-86. http://dx.doi.org/10.1002/hep.23093.

[4] Sunny NE, Bril F, Cusi K. Mitochondrial adaptation in nonalcoholic fatty liver disease: novel mechanisms and treatment strategies. Trends Endocrinol Metab 2017;28:250-60. http://dx.doi.org/10.1016/j.tem.2016.11.006.

[5] Petersen KF, Dufour S, Savage DB, Bilz S, Solomon G, Yonemitsu S, et al. The role of skeletal muscle insulin resistance in the pathogenesis of the metabolic syndrome. Proc Natl Acad Sci U S A 2007;104:12587-94. http://dx.doi.org/ 10.1073/pnas.0705408104.

[6] Mari A, Gastaldelli A, Foley JE, Pratley RE, Ferrannini E. Beta-cell function in mild type 2 diabetic patients: effects of 6-month glucose lowering with nateglinide. Diabetes Care 2005;28:1132-8.

[7] Roden M, Mariz S, Brazzale AR, Pacini G. Free fatty acid kinetics during longterm treatment with pioglitazone added to sulfonylurea or metformin in Type 2 diabetes. J Intern Med 2009;265:476-87. http://dx.doi.org/10.1111/j.13652796.2008.02040.x.

[8] Amigo I, Traba J, González-Barroso MM, Rueda CB, Fernández M, Rial E, et al. Glucagon regulation of oxidative phosphorylation requires an increase in matrix adenine nucleotide content through $\mathrm{Ca} 2+$ activation of the mitochondrial ATP-Mg/Pi carrier SCaMC-3. J Biol Chem 2013;288:7791-802. http:// dx.doi.org/10.1074/jbc.M112.409144. 
[9] Perry RJ, Wang Y, Dufour S, Peng L, Ehrlich BE, Shulman GI. Inositol 1,4,5Trisphosphate Receptor-1 (IP3R1) mediates glucagon-stimulated gluconeogenesis and mitochondrial oxidation. Diabetes 2017;66:A536.

[10] Marques-da-Silva AC, D'Avila RB, Ferrari AG, Kelmer-Bracht AM, Constantin J, Yamamoto NS, et al. Ca2+ dependence of gluconeogenesis stimulation by glucagon at different cytosolic NAD(+)-NADH redox potentials. Braz J Med Biol Res 1997;30:827-36.

[11] Cusi K. The role of adipose tissue and lipotoxicity in the pathogenesis of type 2 diabetes. Curr Diab Rep 2010;10:306-15. http://dx.doi.org/10.1007/s11892010-0122-6.

[12] Roden M, Perseghin G, Petersen KF, Hwang JH, Cline GW, Gerow K, et al. The roles of insulin and glucagon in the regulation of hepatic glycogen synthesis and turnover in humans. J Clin Invest 1996;97:642-8. http://dx.doi.org 10.1172/JCI118460.

[13] Müller WA, Faloona GR, Aguilar-Parada E, Unger RH. Abnormal alpha-cell function in diabetes. Response to carbohydrate and protein ingestion. $\mathrm{N}$ Engl J Med 1970;283:109-15. http://dx.doi.org/10.1056/NEJM197007162830301.

[14] Ohneda A, Watanabe K, Horigome K, Sakai T, Kai Y, Oikawa S. Abnormal response of pancreatic glucagon to glycemic changes in diabetes mellitus. J Clin Endocrinol Metab 1978;46:504-10. http://dx.doi.org/10.1210/jcem-46-3-504.

[15] Alssema M, Rijkelijkhuizen JM, Holst JJ, Teerlink T, Scheffer PG, Eekhoff EMW, et al. Preserved GLP-1 and exaggerated GIP secretion in type 2 diabetes and relationships with triglycerides and ALT. Eur J Endocrinol 2013;169:421-30. http://dx.doi.org/10.1530/EJE-13-0487. 